and public healthcare services to pay attention to the health status and needs of immigrants. Kastrup (2008) proposes a competent treatment of patients with multicultural backgrounds, which demands that mental health professionals be aware of alternative traditional approaches and show an interest and an ability to bridge the more traditional and the Western approaches to treatment. Transcultural psychiatry today is recommended to facilitate 'an understanding about basic mental functions and disease categories, while paying specific attention to culturally influenced constellations of stress factors, psychosocial variables that influence treatment outcome and the individual understanding and interpretation of disease symptoms' (Schouler-Ocak et al, 2008, p. S1).

Healthcare and healthcare systems should be seen and understood in their sociocultural context (Kastrup, 2008). Access barriers remain, as does discrimination. As poor mental health may block the process of acculturation, the mental health of immigrants from East European countries should be paid more attention, particularly with the recent enlargement of the European Union.

\section{References}

Blomstedt, Y., Johansson, S.-E. \& Sundquist, J. (2007) Mental health of immigrants from the former Soviet Bloc: a future problem for primary health care in the enlarged European Union? A cross-sectional study. BMC Public Health, 7, 27.
Carlsson, F., Merlo, J., Lindström, M., et al (2006) Representativity of a postal public health questionnaire survey in Sweden, with special reference to ethnic differences in participation. Scandinavian Journal of Public Health, 34, 132-139.

Fassmann, H. (1994) European East-West migration, 1945-1992. International Migration Review, 28, 520-538.

Hunt, P. (2007) Implementation of General Assembly Resolution 60/251 of 15 March 2006 entitled 'Human Rights Council'. Report of the Special Rapporteur on the right of everyone to the enjoyment of the highest attainable standard of physical and mental health. A HRC/4/28/Add.s, 28 February. United Nations.

Kastrup, M. (2008) Staff competence in dealing with traditional approaches. European Psychiatry, 23, S59-S68.

Nørredam, M., Mygind, A. \& Krasnik, A. (2006) Access to health care for asylum seekers in the European Union - a comparative study of country policies. European Journal of Public Health, 16, 286-290.

Ponizovsky, A. M., Ritsner, M. S. \& Modai, I. (1999) Suicidal ideation and suicide attempts among immigrant adolescents from the former Soviet Union to Israel. Journal of the American Academy of Child and Adolescent Psychiatry, 38, 1433-1441.

Schouler-Ocak, M., Haasen, C. \& Heinz, A. (2008) Migration and transcultural psychiatry in Europe. European Psychiatry, 23, S1-S3.

Skarpsvärd, R.-M. \& Yenidogan, J. (2005) Tryggare kan ingen vara...?! Äktenskapsmigrationens drivkrafter. Sociologi C/D-uppsats, report no. 27. Luleå tekniska universitet, Institutionen för Arbetsvetenskap, Avdelningen för Industriell produktionsmiljö.

Sungurova, Y., Johansson, S.-E. \& Sundquist, J. (2006) East-West health divide and East-West migration: self-reported health of immigrants from Eastern Europe and the former Soviet Union in Sweden. Scandinavian Journal of Public Health, 34, 217-221.

Wintzer, S. (2008) Hälsoundersökningar av asylsökande har ökat. Sveriges kommuner och landsting, http://www.skl.se/artikel.asp?C $=6848 \& A=$ 51775 (accessed May 2008).

\title{
Migration and mental health in Canada: can government policy help?
}

\section{Stephen Kisely}

Chair in Health Outcomes, Department of Psychiatry, Dalhousie University, Halifax, NS, Canada, email Stephen.Kisely@cdha.nshealth.ca

anada admits more than 220000 immigrants every year and this is reflected in the statistic that $18 \%$ of the population was born abroad (Beiser, 2005). However, government policy emphasises the admission of healthy immigrants rather than their subsequent health. Immigrants do not show a consistently elevated rate of psychiatric illness, and morbidity is related to an interaction between predisposition and socio-environmental factors, rather than immigration per se. These factors include forced migration and circumstances after arrival, such as poverty, limited recognition of qualifications, discrimination and isolation from the immigrant's own community. For instance, in Canada more than $30 \%$ of immigrant families live below the official poverty line in the first 10 years of settlement (Beiser, 2005).

Some groups are at higher risk of psychiatric morbidity, such as asylum seekers. In this population, symptoms of depression and anxiety, panic attacks or agoraphobia are common and are often reactions to past experiences and current social circumstances (Kisely et al, 2002). More than $20 \%$ of asylum seekers in Australia reported previous torture, a third reported imprisonment for political reasons, and a similar proportion the murder of family or friends (Silove et al, 2000; Steel \& Silove, 2001; Sultan \& O'Sullivan, 2001). In one British study, $65 \%$ of Iraqi refugees had a history of systematic torture during detention (Gorst-Unsworth \& Goldenburg, 1998). These experiences are compounded by the rigours of reaching safety, social isolation, poverty, hostility and racism (Kisely et al, 2002).

\section{Acculturation}

Although resettlement countries can do little to address presettlement experiences, governments can address issues of unemployment, discrimination and acculturation following 
arrival (Beiser, 2005). Acculturation refers to culture change that results from continuous, direct contact between two independent cultures. This process is known to influence, for example, biological, physical, social, cultural and psychological factors. Aspects include:

o enculturation, which is defined as the degree to which an immigrant adopts the new culture or values relationships with the larger society (and which can be associated with 'culture shock')

o biculturation, which is defined as the degree to which immigrants maintain their cultural identity but also adopt the new culture and larger society (usually in association with access to multiple resources).

Immigrants' responses to acculturation include the following (Beiser, 2005):

assimilation, where the culture of origin is abandoned in favour of the new

integration, where there is a creative blending of the two

o rejection, where the new culture is rejected

o marginalisation, where neither the old nor the new are accepted.

Marginalisation is associated with the greatest risk of psychological morbidity, integration the least.

\section{Government policy and immigrant health}

Government policies can directly compromise health. Some Canadian provinces insist on a waiting period before newly arrived immigrants can have access to public health services. Concerns about uncontrolled migration have encouraged some destination countries to adopt policies of deterrence, in which increasingly restrictive measures are being imposed on asylum seekers (Kisely et al, 2002). In Australia these include confinement in detention centres, restriction of the right to appeal, and temporary rather than permanent asylum. These policies may be counter-productive, in that they can aggravate pre-existing medical problems and may actually compromise public health.

Some asylum seekers are held in detention facilities for considerable periods of time. An Australian report identified more than 80 detainees who had been held in detention for between 2 and 5 years (Human Rights and Equal Opportunity Commission, 1998). Housing refugees in crowded conditions can facilitate the spread of infectious disease. In America, 90 asylum seekers contracted tuberculosis from a fellow detainee. Detention may also harm the mental health of asylum seekers. Asylum seekers in detention have high rates of attempted suicides and hunger strikes. They also show significantly higher levels of depression, suicidal ideation, post-traumatic stress, anxiety and panic attacks than asylum seekers, refugees and immigrants from the same country living in the community (Silove et al, 2000). In Australia, the Human Rights and Equal Opportunity Commission (1998) has suggested that the boredom and frustration of prolonged detention together with social isolation may be responsible for outbreaks of violence, including domestic violence, among detainees and between detainees and officials. Single women and children may be at increased risk of abuse and exploitation when confined in mixed-gender detention facilities (Silove et al, 2000).

\section{Where do immigrants settle in Canada?}

Most immigrants settle in Toronto, Vancouver or Montreal, and they have lower suicide rates than those who go elsewhere in Canada. This is confirmed in studies that show reduced rates of mental illness where there is a like-ethnic critical mass. Immigrants prefer to settle in these urban centres for three reasons:

o increased closeness to family or similar ethnic groups

O enhanced employment opportunities

O improved access to support services that help with integration into Canadian society.

\section{The challenge for smaller provinces}

The dilemma for smaller provinces is evident in the statistics presented in Fig. 1. When immigration trends by province are examined, $90 \%$ of newcomers go to three provinces: Ontario, Quebec and British Columbia. Smaller provinces must find a way to attract and retain immigrants in ways that maximise their physical and mental health. Policies that direct newly arrived entrants to low-density areas where there are few immigrants run counter to research evidence of the health benefits of like-ethnic communities (Beiser, 2005). Such policies also ignore the association between dispersion and compromised mental health (Beiser, 2005).

Manitoba's approach has been of particular interest. In spite of its relatively small population (1 million), Manitoba has consistently ranked fifth among provinces in attracting immigrants and is seeing increasing success in retention (Fig. 1)

Manitoba's government set an annual target of 10000 arrivals, with strategies both to attract newcomers to the province and to keep them there (Manitoba Labour and Immigration, 2005). One component is the Manitoba Provincial Nominee Program (MPNP), which is an economic programme that nominates skilled workers for permanent resident status in Canada. It also assists with adult language training and the recognition of qualifications. Manitoba's immigration programme is run by the Immigration and Multiculturalism Division, which comprises:

adult language training services

o settlement and labour market services

immigration promotion and recruitment

o multiculturalism secretariat

a strategic planning and programme support

$O$ an executive administration.

Another component of the strategy is the creation of the Manitoba Immigration Council, an appointed 12-member body with representation from business, labour, multicultural organisations and educational institutions. The Council provides advice in three key areas: attracting immigrants; provision and development of settlement services; and complementing the development of crucial supports to retain immigrants in Manitoba.

Having arrived in Manitoba, provincial policy seeks to maximise retention by providing:

O employment opportunities, through awareness of labour market needs and willingness on the part of employers to hire immigrants

o affordable and available housing (including temporary accommodation) 


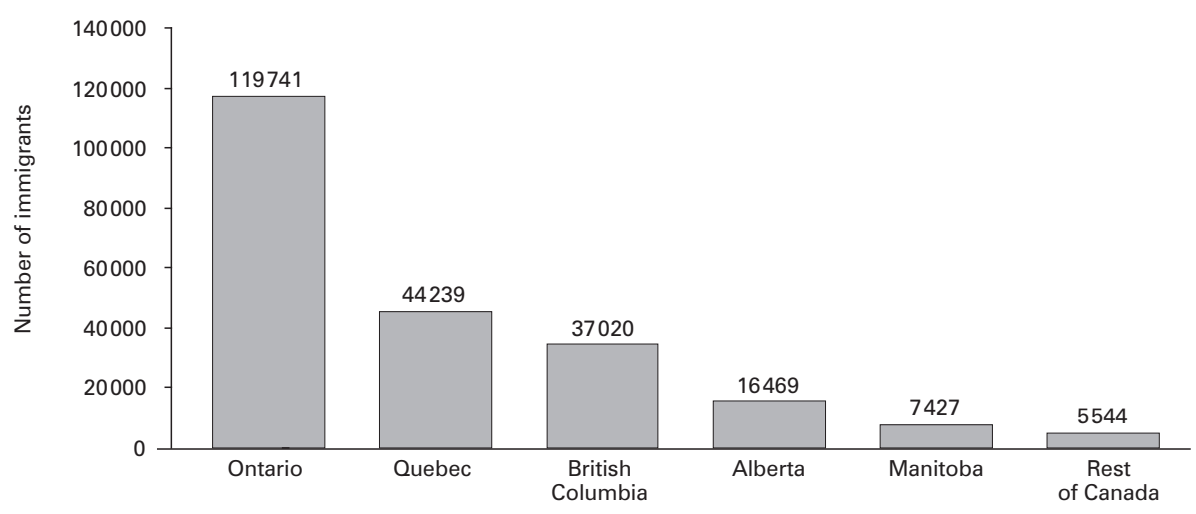

Fig. 1 Immigration by Canadian province or territory, 2004.

O settlement and integration support (information, orientation, referral, counselling, accessible programmes)

o language training (full time, part time, community, workplace, specific purposes, accessible programmes)

$\checkmark$ access to health, education and social programmes (interpretation, cross-cultural awareness)

o community support and appreciation of diversity

o cultural and recreational opportunities.

\section{Does it work?}

One way of assessing efficacy is to compare Manitoba, which has a population of approximately 1 million, to a similar jurisdiction of roughly the same population, such as Nova Scotia. While Manitoba has its well-established MPNP and Immigration Council, to make it easier for highly skilled immigrants to find employment in occupations for which they have training and experience, such innovation has been absent until recently in Nova Scotia. In 1995, 3500 immigrants settled in each province. Ten years later this had increased to 7427 in Manitoba and fallen to 1770 in Nova Scotia. This difference was statistically significant. Retention rates also differed.

The Manitoban programme has informed the development of a similar strategy in Nova Scotia (Immigration Office, 2005). The province has now established an Immigration Office, consolidating all provincial immigration activities into one location, and set 5-year targets for both doubling the number of immigrants and increasing the retention rate from $40 \%$ to $70 \%$.

\section{Conclusions}

Government policy can have direct effects on the attraction and retention of immigrants, as well as on their subsequent mental health. Ill-considered initiatives such as denying access to healthcare and not recognising qualifications, or encouraging dispersion, can worsen outcomes. Restrictive policies towards certain groups, such as asylum seekers, can be particularly harmful. On the other hand, policies that recognise the importance both of maximising employment opportunities and of the support of like-ethnic communities can benefit both immigrants and the host country.

Physicians can contribute constructively to the debate in several ways at an individual and collective level. We need to ensure sufficient medical support for detention centres, as well as continuity of treatment programmes on discharge to the community. There is a fine balance between ensuring that asylum seekers receive appropriate healthcare and collusion with a system of detention that is potentially harmful to health. As a profession, we should also be lobbying for migrants' access to healthcare and other government services, to break the cycle of poverty, ill-health and limited access to health services. Lastly, doctors should set an example within their own profession by streamlining the recognition of qualifications for international medical graduates.

\section{References}

Beiser, M. (2005) The health of immigrants and refugees in Canada. Canadian Journal of Public Health, 96, S30-S44.

Gorst-Unsworth, C. \& Goldenburg, E. (1998) Psychological sequelae of torture and organised violence suffered by refugees from Iraq: trauma-related factors compared with social factors in exile. British Journal of Psychiatry, 172, 90-94.

Human Rights and Equal Opportunity Commission (1998) Those Who've Come Across the Seas: The Report of the Commission's Inquiry Into the Detention of Unauthorised Arrivals. Commonwealth of Australia.

Immigration Office (2005) Nova Scotia's Immigration Strategy Halifax: Province of Nova Scotia. Available at http://www.gov.ns.ca/ immigration (accessed 9 May 2008).

Kisely, S., Stevens, M., Hart, B., et al (2002) Health issues of asylum seekers and refugees. Australian and New Zealand Journal of Public Health, 26, 8-10.

Manitoba Labour and Immigration (2005) Growing Through Immigration: An Overview of Immigration and Settlement in Manitoba. Immigration and Multiculturalism Division of Manitoba Labour \& Immigration. Available at http://www.gov.mb.ca/labour/immigrate/ infocentre/pdf/mb_settle_present june05.pdf (accessed 9 May 2008).

Silove, D., Steel, Z. \& Watters, C. (2000) Policies of deterrence and the mental health of asylum-seekers. JAMA, 284, 604-611.

Steel, Z. \& Silove, D. (2001) The mental health implications of detaining asylum-seekers. Medical Journal of Australia, 175, 596-599.

Sultan, A. \& O'Sullivan, K. (2001) Psychological disturbance in asylumseekers held in long term detention: a participant-observer account. Medical Journal of Australia, 175, 593-596. 